\title{
Assessment of MTI Water Temperature Retrievals with Ground Truth from the Comanche Peak Steam Electric Station Cooling Lake WSRC-TR-2002-00381
}

\author{
Malcolm M. Pendergast* \\ Robert. J. Kurzeja ${ }^{* *}$ \\ * SMP Enterprises \\ Martinez. GA \\ ** Westinghouse Savannah River Company
}


This document was prepared in conjunction with work accomplished under Contract No. DE-AC09-96SR18500 with the U. S. Department of Energy.

\section{DISCLAIMER}

This report was prepared as an account of work sponsored by an agency of the United States Government. Neither the United States Government nor any agency thereof, nor any of their employees, makes any warranty, express or implied, or assumes any legal liability or responsibility for the accuracy, completeness, or usefulness of any information, apparatus, product or process disclosed, or represents that its use would not infringe privately owned rights. Reference herein to any specific commercial product, process or service by trade name, trademark, manufacturer, or otherwise does not necessarily constitute or imply its endorsement, recommendation, or favoring by the United States Government or any agency thereof. The views and opinions of authors expressed herein do not necessarily state or reflect those of the United States Government or any agency thereof.

This report has been reproduced directly from the best available copy.

Available for sale to the public, in paper, from: U.S. Department of Commerce, National Technical Information Service, 5285 Port Royal Road, Springfield, VA 22161, phone: (800) 553-6847, fax: (703) 605-6900

email: orders@ntis.fedworld.gov

online ordering: http://www.ntis.gov/help/index.asp

Available electronically at http://www.osti.gov/bridge

Available for a processing fee to U.S. Department of Energy and its contractors, in paper, from: U.S. Department of Energy, Office of Scientific and Technical Information, P.O. Box 62, Oak Ridge, TN 37831-0062,

phone: (865)576-8401,

fax: (865)576-5728

email: $\underline{\text { reports@ adonis.osti.gov }}$ 


\section{Table of Contents}

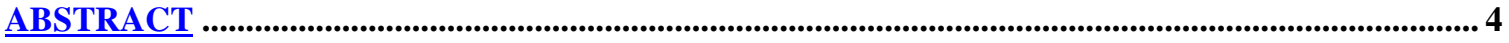

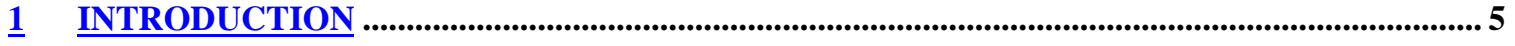

$\underline{2}$ METHODOLOGY

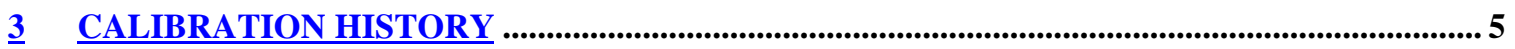

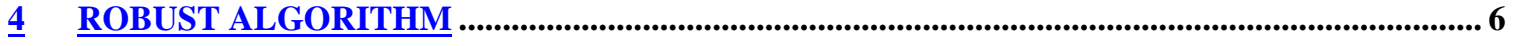

$\underline{5}$ GROUND TRUTH DATA

$\underline{6}$ UNCERTAINTY IN THE GROUND TRUTH DATA...................................................................... 7

7 MTI WATER SURFACE TEMPERATURE IMAGE DATA...................................................8

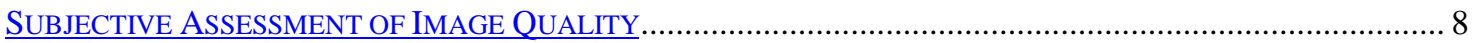

PROCEDURE FOR SELECTING REPRESENTATIVE WATER SURFACE TEMPERATURES ..................................... 8

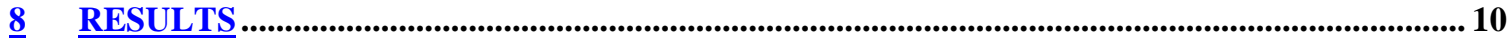

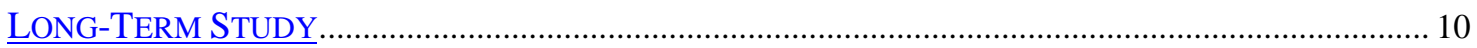

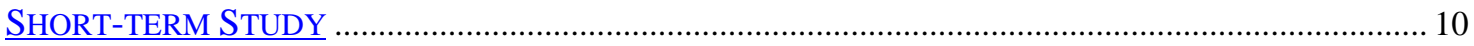

9 CONCLUSIONS .................................................................................................................................... 11

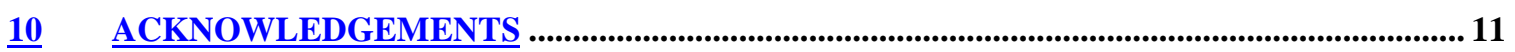

11 REFERENCES....................................................................................................................... 12

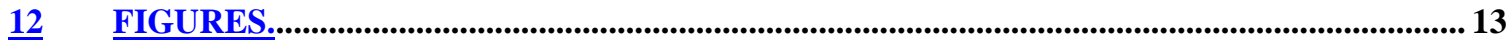

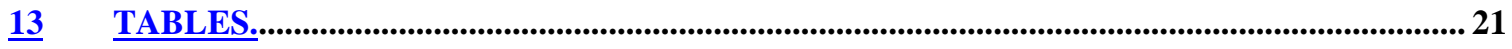




\section{List of Figures}

FIGURE 1. NADIR ROBUST COEFFICIENTS. HOT COEFFICIENTS ARE USED FOR T >315K, COLD COEFFICIENTS FOR T<300K AND MERGED VALUES FOR 300K-315K. FROM ATKINS ET AL. (2001) 13

FiguRE 2. LoCATION OF GRound TRUTH OBSERVATION BUOYS AT COMANCHE PEAK.............. 14

FIGURE 3. WATER SURFACE TEMPERATURE IMAGE FOR COMANCHE PEAK FOR 9/6/00 ................ 15

FIGURE 4. IMAGE QUALITY FOR 16 DAYTIME MTI IMAGES OF COMANCHE PEAK........................ 16

FIGURE 5. QUALITY FACTOR OF 11 NIGHTTIME MTI IMAGES FOR COMANCHE PEAK.................. 17

FIGURE 6. SUB-SAMPLED IMAGE OF COMANCHE PEAK SHOWING REGIONS-OF-INTEREST ASSOCIATED WITH HOT-WATER DISCHARGE AND COLD-WATER INTAKE................................... 18

FIGURE 7. WATER TEMPERATURE RETRIEVAL ERROR AND IMAGE QUALITY FOR NIGHTTIME AT COMANCHE PEAK SCA 1.

FIGURE 8. WATER TEMPERATURE RETRIEVAL ERROR AND IMAGE QUALITY FOR DAYTIME AT COMANCHE PEAK SCA 1.

\section{List of Tables}

TABLE 1. COEFFICIENTS FOR CALCULATING WST FROM TOP-OF-ATMOSPHERE BRIGHTNESS TEMPERATURES OF MTI THERMAL BANDS FOR ZENITH-TO-MTI ANGLES RANGING FROM 0 TO 40 DEGREES. (PROVIDED BY WILLIAM B. CLODIUS, LANL 1/28/02)

TABLE 2. SPATIAL ERROR OF WATER SURFACE TEMPERATURE FOR LONG-TERM STUDY AT COMANCHE

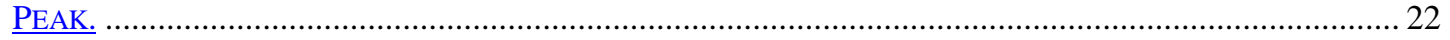

TABLE 3. ERROR ANALYSIS OF WATER SURFACE TEMPERATURE FOR LONG-TERM STUDY AT COMANCHE

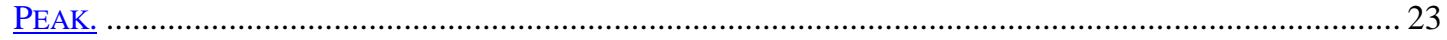

TABLE 4. SPATIAL ERROR OF WATER SURFACE TEMPERATURE FOR SHORT-TERM STUDY AT COMANCHE

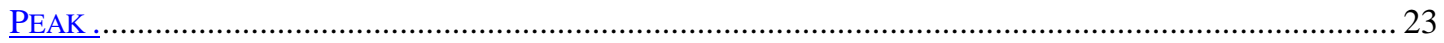

TABLE 5. ERROR ANALYSIS FOR WATER SURFACE TEMPERATURE FOR SHORT-TERM STUDY AT COMANCHE

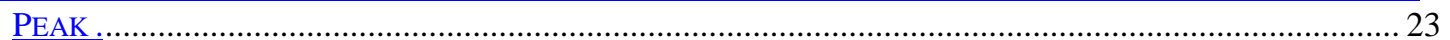

TABLE 6. LISTING OF ALL DATA USED IN THE LONG-TERM STUDY FOR THE EVALUATION OF WST-R........... 24

TABLE 7. LISTING OF COLUMN HEADINGS AND DEFINITIONS FOR TABLE 6............................................... 26

TABLE 8. SUMMARY OF WATER SURFACE TEMPERATURE ERRORS, ADJUSTED GROUND TRUTH - WST-R, DURING LONG-TERM STUDY AT COMANCHE PEAK AS FUNCTION OF TIME OF DAY AND SCA.................. 27

TABLE 9. SUMMARY OF WATER SURFACE TEMPERATURE ERRORS, ADJUSTED GROUND TRUTH - WST-R,

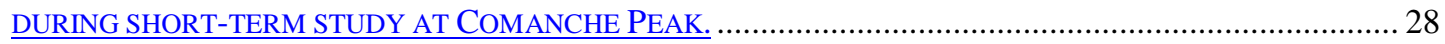




\begin{abstract}
Surface water temperatures calculated from Multispectral Thermal Imager (MTI) brightness temperatures and the robust retrieval algorithm, developed by the Los Alamos National Laboratory (LANL), are compared with ground truth measurements at the Squaw Creek reservoir at the Comanche Peak Steam Electric Station near Granbury Texas. Temperatures calculated for thirty-four images covering the period May 2000 to March 2002 are compared with water temperatures measured at 10 instrumented buoy locations supplied by the Savannah River Technology Center.
\end{abstract}

The data set was used to examine the effect of image quality on temperature retrieval as well as to document any bias between the sensor chip arrays (SCA's). A portion of the data set was used to evaluate the influence of proximity to shoreline on the water temperature retrievals. This study found errors in daytime water temperature retrievals of $1.8 \mathrm{C}$ for SCA 2 and $4.0 \mathrm{C}$ for SCA 1. The errors in nighttime water temperature retrievals were $3.8 \mathrm{C}$ for SCA 1.

Water temperature retrievals for nighttime appear to be related to image quality with the largest positive bias for the highest quality images and the largest negative bias for the lowest quality images. The daytime data show no apparent relationship between water temperature retrieval error and image quality.

The average temperature retrieval error near open water buoys was less than corresponding values for the near-shore buoys. After subtraction of the estimated error in the ground truth data, the water temperature retrieval error was $1.2 \mathrm{C}$ for the open-water buoys compared to $1.8 \mathrm{C}$ for the near-shore buoys. The open-water error is comparable to that found at Nauru. 
This report evaluates MTI-derived surface water temperature in the Squaw Creek reservoir at the Comanche Peak Steam Electric Station near Granbury Texas. The MTI water surface temperature, WST-R, was determined by the Los Alamos National Laboratory based on the 'robust retrieval' (Tornow and Borel, 1994 and Tornow et al, 1994). This report utilizes 27 MTI images collected during the periods from May 2000 to September 2001 and 7 MTI images collected from March 5 to April 10, 2002. These two data sets make up the long-term and shortterm studies, respectively. Complete details describing the ground truth measurements are contained in the Comanche Peak data report (Parker and Garrett, 2002).

The long-term data set consists of three monitoring buoys, one in the warm-water discharge flow (shown as "OBL"), a second at the plant water intake (shown as "Intake"), and a third in the safe shutdown impoundment (shown as "SSI") in Figure 1. These locations were intended to capture temperature extremes of the lake at any given time.

The short-term data set consists of ten monitoring buoys shown in Figure 1 as: "SSI", "IO", "OBL", "Bubbler Buoy", "Alternate Lake Discharge", "A", "B", "C", and "D". The buoys A-D were chosen near the center of the pond in order to minimize any effects from the shore. This period also coincided with an unusual orbit of MTI whereby the same location could be consecutively imaged for about two weeks.

\section{$2 \quad$ Methodology}

Both data sets were used to evaluate the WST-R temperature against ground truth data. The long term data set was used to examine the effect of image quality on temperature retrieval as well as to document any bias between the sensor chip arrays, SCA's. The short-term data set was used to evaluate the influence of proximity to shoreline to the WST-R assessment. Methods used to analyze the Comanche Peak data are based upon methods used to evaluate WST-R in the tropical western Pacific at the island of Nauru (Kurzeja and Pendergast, 2002).

\section{$3 \quad$ Calibration History}

The calibration history of the MTI was discussed by Atkins et al. (2001). They asserted that the $1 \%$ design accuracy in the IR bands had probably been achieved after launch but noted variability in the brightness temperature between the three SCA's of up to $\sim 0.5 \mathrm{C}$ for uniform sea-water targets in bands $\mathrm{K}$ and $\mathrm{L}$. They argued that this variability was probably caused by uncertainty in the individual SCA filter functions, especially at short wavelengths, and was not due to radiometric differences. Thus, the brightness temperature of the SCA's would be expected to vary from scene to scene and Atkins et al. estimated this effect to be $\sim 0.5 \mathrm{C}$ for band $\mathrm{L}$.

On Oct 31, 2001 the MTI Telescope and Calibration Control Unit (TCAL) experienced a power failure. This shut down the optical assembly operational heaters (with a $\sim 28 \mathrm{C}$ decrease in temperature), and caused the loss of the secondary mirror focus adjustment, door assembly, black body panel, visible panel, and quick calibration wheel assembly. After this failure, the calibration sequence was replaced by two deep-space looks. Periodic moon looks and ground calibration are being used to monitor changes in performance.

The quality of the MTI radiances, particularly in the IR, grew worse after the Oct 31, 2000 TCAL failure and greater offsets between the SCA's and linear variations in radiance across individual SCA's were observed. These have been attributed to thermally-induced mechanical shifts in the 
optics. This problem has been corrected by viewing targets with the satellite rotated by 90 degrees, i.e., viewing the same area with all pixels in each SCA. Differences between the SCA's have been corrected by normalizing SCA's 2 and 3 to the high end of SCA2, which also improved consistency with SCA1. Variations in radiance within SCA's have been corrected with 90 degree looks at uniform ocean targets.

The loss of the black body panels also precludes non-linear corrections in the radiance values and calibration of individual pixels. These corrections were maintained as before the TCAL failure.

In summary, Atkins et al. (2001) estimated a degradation in the inferred surface temperatures of 0.5-3.0C in brightness temperatures after the TCAL failure, with more specific estimates reserved for a later date.

\section{$4 \quad$ Robust Algorithm}

The MTI product evaluated in this report is called the Robust Water Surface Temperature, WST$\mathrm{R}$, referred to as WST in this report . This product was supplied to SRTC by the Los Alamos National Laboratory, and consists of a single band image with a resolution of $20 \mathrm{~m}$. The values are floating point and in degrees Kelvin. The WST algorithm utilizes several sets of coefficients that are applied to Top-of-Atmosphere Brightness temperatures, TOAB, of MTI bands J, K, L, M and $\mathrm{N}$ as a function of the Zenith-to-MIT angle. TOAB values can be generated internally within the algorithm or obtained as one of the MTI products and the angle, Zenith2MTI, is obtained from the MTI image header text file.

The Robust algorithm includes 4 sets of coefficients for use with cold or hot targets and in day or night. The 'hot' coefficients are used for targets warmer than $315 \mathrm{~K}$ and the 'cold' coefficients when the target is cooler than 300C. The two sets are merged for temperature between $300 \mathrm{~K}$ and $315 \mathrm{~K}$. The coefficient sets are shown in Figure 1 for nadir viewing angles and the hot coefficients are listed in more detail in Table 1 Tornow and Borel (1994) derived the coefficients from LOWTRAN simulations of 380 different atmospheres. Although both nadir and backward looks can be used to calculate robust temperatures, only the nadir look has been used in this study.

TDAY $_{\mathrm{WST}}$ and TNITE $\mathrm{WST}_{\mathrm{T}}$ use the same coefficients for the three SCA's, despite known biases between the SCA's. Thus, one result from this study is to document the magnitude of these biases.

\section{$5 \quad$ Ground truth data}

The direct measurement of the water surface temperature is difficult and requires infrared radiometers because the surface skin layer is very thin $(<<1 \mathrm{~mm})$ and is cooler than the deeper 'bulk' water. It is easier to accurately measure the deeper bulk water temperature but this temperature must be adjusted to account both for the cool skin and for any temperature gradient between the bulk water sensor and the near-surface temperature (warm-layer effect). The groundtruth water temperature measurements at Comanche Peak were conducted as close to the surface as possible $(12 \mathrm{~cm})$ so that the warm layer effect could be ignored.

Temperature measurements were made with small self-contained data loggers. The initial sensors were Hugrun Seamon Mini ${ }^{\circledR}$, but Hugrun went out of business in 2000, so the StowAway 
TidbiT®, manufactured by Onset Computer (www.onsetcomputer.com), was used thereafter. All sensors were suspended approximately $12 \mathrm{~cm}$ below small PVC floats or, at sites A, B, C, D, IO, and SSI, below a large marker buoy. Small floats manufactured by Onset Computer were attached to permanent buoys at the OBL, Bubbler Buoy, Alternate Lake Discharge, and Intake sites.

All Seamon Mini data were collected at hourly intervals, all Tidbits were collected at 30 minute intervals, except for the March 5 - April 10, 2002 data which were collected at 15 minute intervals.

In order to compare near surface bulk water temperatures with those inferred from satellite, it is necessary to correct for the cool skin. This effect is a complicated function of heat exchange at the sea surface and ranges between 0.0 and $-1.5 \mathrm{C}$. For the long-term study we adopt the results obtained by Garrett (personal communication) from which the skin temperature effect varied from $-0.5 \mathrm{C}$ during Summer to $-1.0 \mathrm{C}$ during winter. A skin temperature effect of $-0.8 \mathrm{C}$ was used for the short-term study.

\section{$6 \quad$ Uncertainty in the ground truth data.}

To better interpret the relationship between WST-R and observations it was necessary to examine the uncertainties associated with the adjustments to the observed bulk-water temperatures. The various components are: sensor accuracy, skin-temperature effect and spatial variability.

The sensor accuracy was taken as $0.2 \mathrm{C}$ and the error associated with the estimate of the skintemperature effect was taken as $0.2 \mathrm{C}$. The estimate for spatial variability was made using the WST-R image data for the two data sets used in the study.

The spatial error for the long-term study is assumed to be equal to the standard deviation of the 16 WST-R values centered at each buoy location. The spatial error for the short-term study is assumed to be equal to the standard deviation of the 9 WST-R values centered at each buoy location.

Table 2 shows spatial errors for the intake and discharge buoy for each image during the longterm study. The average, minimum and maximum values are shown at the bottom of each column. The average values for the intake and discharge are 0.19 and $0.20 \mathrm{C}$, respectively and the maximum values are 0.35 and $0.43 \mathrm{C}$. Table 3 shows the error analysis for the long-term study and an expected total error for the bulk-water temperature adjustment between 0.35 and $0.50 \mathrm{C}$.

Table 4 shows spatial errors for 10 buoys for 8 images during the short-term study with average, minimum and maximum values at the bottom of each column. The average values are generally $50 \%$ larger than the values for the long-term study and maximum values about 4 times larger than the values for the long-term study. Table 5 shows the error analysis for the short-term study with data grouped into two categories, near-shore and open-water. The total error for the nearshore buoys ranges between 0.55 and $1.38 \mathrm{C}$ and between 0.38 and $0.78 \mathrm{C}$ for the open-water buoys. 


\section{$7 \quad$ MTI Water Surface Temperature Image Data}

Figure 2 shows an image of the Robust Water Surface Temperature for 9/06/00 showing the discontinuity at the junction of the central SCA and eastern SCA near the eastern portion of the cooling pond. [ For daytime images, the western, center and eastern sections of the image are SCA2, SCA1 and SCA3, respectively. At night the western and eastern sections of the image are reversed, i.e., SCA 3 and SCA 2 are west and east, respectively. In this report SCA's will be referred to as east, center and west to eliminate confusion.] Water temperature retrieval studies for Nauru (Kurzeja and Pendergast, 2002) have shown that the center SCA is biased high by about $1 \mathrm{C}$ and the eastern and western SCA are within $0.2 \mathrm{C}$ of ground truth. Several factors influenced the selection of images to be used in the evaluation of MTI water surface temperature retrievals. The most important factor was to compile a large enough database to make conclusions statistically significant and next, to select images to cover at least one annual cycle. The initial selection produced a list of 46 images covering the period 5/19/00 to 9/27/01. The initial screening used rather "loose" selection criteria that required at least $50 \%$ of the MTI image be cloud-free. As the study proceeded, images were ranked according to a subjective quality factor based on the presence of clouds. To eliminate any bias in the results, this process did not utilize the ground truth data, but was based upon inspection of the WST-R image and "quicklook" images of the sub-visible cirrus band (MTI band h). The following sections illustrate the procedure.

\section{Subjective Assessment of Image Quality}

27 MTI images (11 nighttime and 16 daytime) were used in the evaluation of WST-R at Comanche Peak, Steam Electric Station covering a period of 15 months with a variety of weather conditions. All images were given a rank number with highest quality associated with smallest rank number. Figure 3 shows daytime images as false color with red and blue represented with MTI band $h$ and green represented with MTI band g. Figure 4 shows nighttime images as false color with red, green and blue represented by MTI bands j, k and 1 respectively. The images were ranked with lowest quality shown in the upper left corner (16) and highest quality shown in the lower right corner (1). The ranking for the daytime images is based upon a combination of the amount of cumulus cloud cover and sub-visible cirrus as determined from MTI band $\mathrm{h}$. The ranking for nighttime images is based upon extent of cloud coverage and clarity of the image.

\section{Procedure for Selecting Representative Water Surface Temperatures}

Figure 5 shows the base map used to register all WST-R images used for the long-term study.

All MTI images were geo-registered to the base map by the author using the ENVI software package with a minimum of 7 control points. The two squares represent areas-of-interest used to extract water surface temperatures at the intake and discharge from the registered WST-R images. The squares represent an area $80 \mathrm{~m}$ by $80 \mathrm{~m}$ consisting of 16 MTI pixels. The square representing the cold-water intake is located about $40 \mathrm{~m}$ north of the actual ground-truth measurement buoy in order to reduce errors caused by strong thermal gradients near the shoreline. The square representing the discharge is centered on the ground-truth buoy.

Registration of the WST-R images used for the short-term study was done by LANL using the most recent geo-registration procedure (Paul Pope, personal communication). Water surface temperatures were extracted from the WST-R images at 10 regions-of-interest centered at each 
WSRC-TR-2002-00381

buoy location shown in Figure 1. The regions-of-interest are $60 \mathrm{~m}$ by $60 \mathrm{~m}$ consisting of 9 MTI pixels centered on each buoy location. 


\section{$8 \quad$ Results}

\section{Long-Term Study}

Table 6 shows a summary of all data in the long-term study. The data have been grouped in order that temperature retrieval errors could be evaluated in terms of time of day, SCA, location and image quality. Table 7 lists all column headings and definitions used in Table 6.

Table 8 summarizes the temperature errors as function of time of day and SCA. The temperature error is taken as the difference between the adjusted ground truth and the corresponding WST-R values at the intake and discharge as shown in Figure 5. The MTI satellite orbit and acquisition geometry caused the buoy locations to be within SCA 1 for 18 of the 27 images and the remaining 9 within SCA 2 . Most of the imagery containing the buoy locations within SCA 2 were daytime images so Table 8 does not show any results for nighttime SCA 2.

Table 8 shows the bias for all cases for SCA 1 at the intake and discharge buoys is $-1.48 \mathrm{C}$ and $-1.66 \mathrm{C}$, respectively, and the RMS error for the intake and discharge buoys is 4.13 and 3.66 $\mathrm{C}$, respectively. Table 8 also shows little day/night difference at the discharge buoy but a considerable difference at the intake buoy. For example, the nighttime bias is $0.82 \mathrm{C}$ whereas the daytime bias is $-4.11 \mathrm{C}$. Table 8 shows much smaller errors for SCA 2 than SCA 1. For example, the daytime bias is $-4.11 \mathrm{C}$ for SCA 1 and $-1.68 \mathrm{C}$ for SCA 2 at the intake buoy and $-1.74 \mathrm{C}$ and $0.59 \mathrm{C}$ for the discharge buoy, respectively. The smaller bias for SCA 2 produces correspondingly smaller RMS errors as shown in Table 8.

Combining results from both intake and discharge buoys gives a daytime temperature bias of $-2.93 \mathrm{C}$ for SCA 1 and $-0.55 \mathrm{C}$ for SCA 2. The corresponding RMS errors for SCA1 and SCA2 are 4.04 and $1.85 \mathrm{C}$, respectively. This would indicate that errors in daytime WST-R retrievals is $1.79 \mathrm{C}$ for SCA 2 and $3.99 \mathrm{C}$ for SCA 1. Applying similar logic the errors in nighttime WST-R retrievals is $3.78 \mathrm{C}$ for SCA 1.

Figure 6 shows a plot of water temperature retrieval error and image quality for nighttime conditions at Comanche Peak. The results for both intake and discharge buoy indicate largest positive bias for the highest quality images and largest negative bias for the lowest quality images after excluding data for the image corresponding to image quality 10. Figure 7 shows a plot of water temperature retrieval error and image quality for daytime conditions. The daytime data show no apparent relationship between water temperature retrieval error and image quality.

\section{Short-term Study}

Table 9 shows a summary of water surface temperature retrieval errors for the short-term study conducted at Comanche Peak during nighttime in March 2002. The table is arranged with the first 6 columns showing results for the buoy locations classified as "near-shore". These locations are plotted in Figure 1 with yellow symbols and yellow labels. The last four columns show results for the buoy locations classified as "open-water". These locations are plotted in Figure 1 with yellow symbols and red labels. Bias and RMS Error are shown at the bottom of the table for each buoy location as well as values for locations grouped as near-shore and open-water.

Considerable variation is seen in the bias and RMS error from site to site with largest values occurring at the near-shore buoys. The average bias the open-water buoys, $-0.06 \mathrm{C}$, and the standard deviation, $1.24 \mathrm{C}$, is less than the corresponding values for the near-shore buoys which 
are $0.29 \mathrm{C}$ and $1.85 \mathrm{C}$, respectively. The better results for the open-water buoys are due to more uniform water temperature and the absence of adjacency effects in the WST retrievals.

The error in the MTI temperatures can be separated from the ground truth uncertainty by subtracting the error variance from Table 5 from the total variance, for example, the MTI error for the open water buoys is given by,

$$
\text { MTI error }=\operatorname{sqrt}\left(1.24^{2}-0.38^{2}\right)=1.18 \mathrm{C} .
$$

The MTI error for the near shore buoys is $1.77 \mathrm{C}$. The open water result is comparable to the clear-sky result obtained at Nauru ( 1C).

\section{Conclusions}

The results of the long-term Comanche Peak study indicate that, after allowing for errors in the ground truth data, the error in daytime water temperature retrievals is $1.8 \mathrm{C}$ for SCA 2 and $4.0 \mathrm{C}$ for SCA 1. The error in nighttime water temperature retrievals is $3.8 \mathrm{C}$ for SCA 1.

Water temperature retrievals for nighttime appear to be related to image quality with largest positive bias for the highest quality images and largest negative bias for the lowest quality images. The daytime data show no apparent relationship between water temperature retrieval error and image quality.

The average temperature retrieval error for the open-water is less than the corresponding values for the near-shore buoys. Reducing the deviations by the estimated error in the ground truth data indicates water temperature retrieval errors are $1.2 \mathrm{C}$ for the open-water buoys and $1.8 \mathrm{C}$ for the near-shore buoys.

\section{Acknowledgements}

We are grateful to Bill Claudius of Los Alamos National Laboratory for providing valuable information on the LANL robust method and to Kim Pollack and Kim Starkovich of LANL for processing the MTI images used in this study. We appreciated the assistance of Paul Pope for providing geo-registration for the March 2002 imagery. 


\section{References}

Atkins, W., S. Bender, W. Christensen, C. Little E. Riddle, 2001. The Multispectral Thermal Imager Calibration. Presented at the MultiSpectral Thermal Imager Symposium, Sandia National Laboratory, March 12-13, 2001.

Fairall, C. W., E.F. Bradley, J.S. Godfrey, G. A. Wick, J.B. Edson, and G. S. Young, 1996. Coolskin and warm-layer effects on sea surface temperature. J. Geophys. Res, 101, 1295-1308.

Kurzeja, R. J. and M. M. Pendergast, 2002. Comparison of MTI and Ground Truth Sea Surface Temperatures at Nauru. Westinghouse Savannah River Company, WSRC-TR-2002-00294.

Parker, M. J. and A. J. Garrett, 2002. Final MTI Final MTI Data Report: Comanche Peak Steam Electric Station. Westinghouse Savannah River Company, WSRC-TR-2002-00374.

Tornow,C. and C. C. Borel, 1994. Multi-angular multi-spectral night-time water temperature retrieval. MTI Technical Report MTI-94-001.

Tornow, C. C.C. Borel, and B. J. Powers, 1994. Robust water temperature retrieval using multispectral and multi angular IR measuremnets, Proc. IGARSS '94, 441-443, 1994. 
12 Figures.

\section{Nadir Robust WST Coefficients}

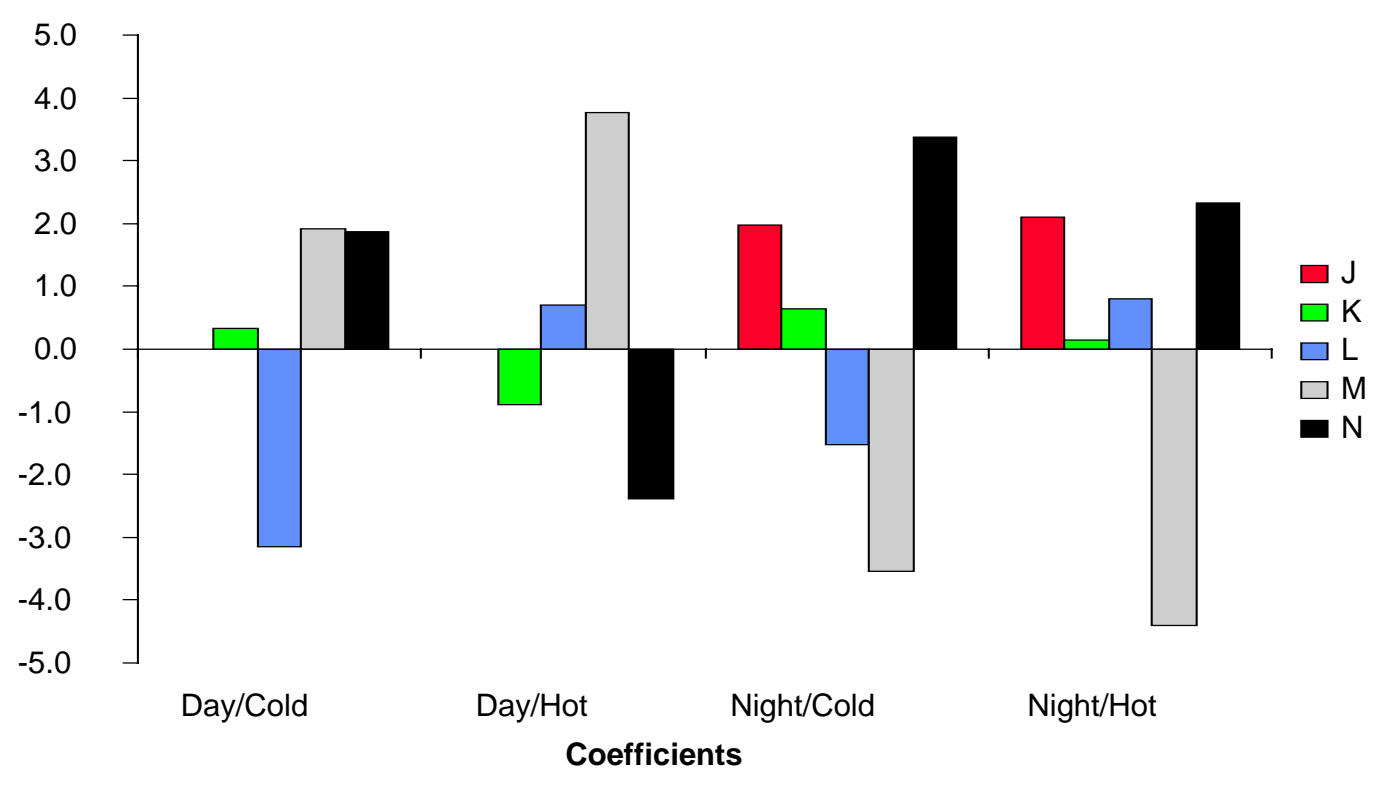

Figure 1. Nadir Robust coefficients. Hot coefficients are used for $\mathrm{T}>315 \mathrm{~K}$, cold coefficients for $T<300 \mathrm{~K}$ and merged values for $300 \mathrm{~K}-315 \mathrm{~K}$. From Atkins et al. (2001) 


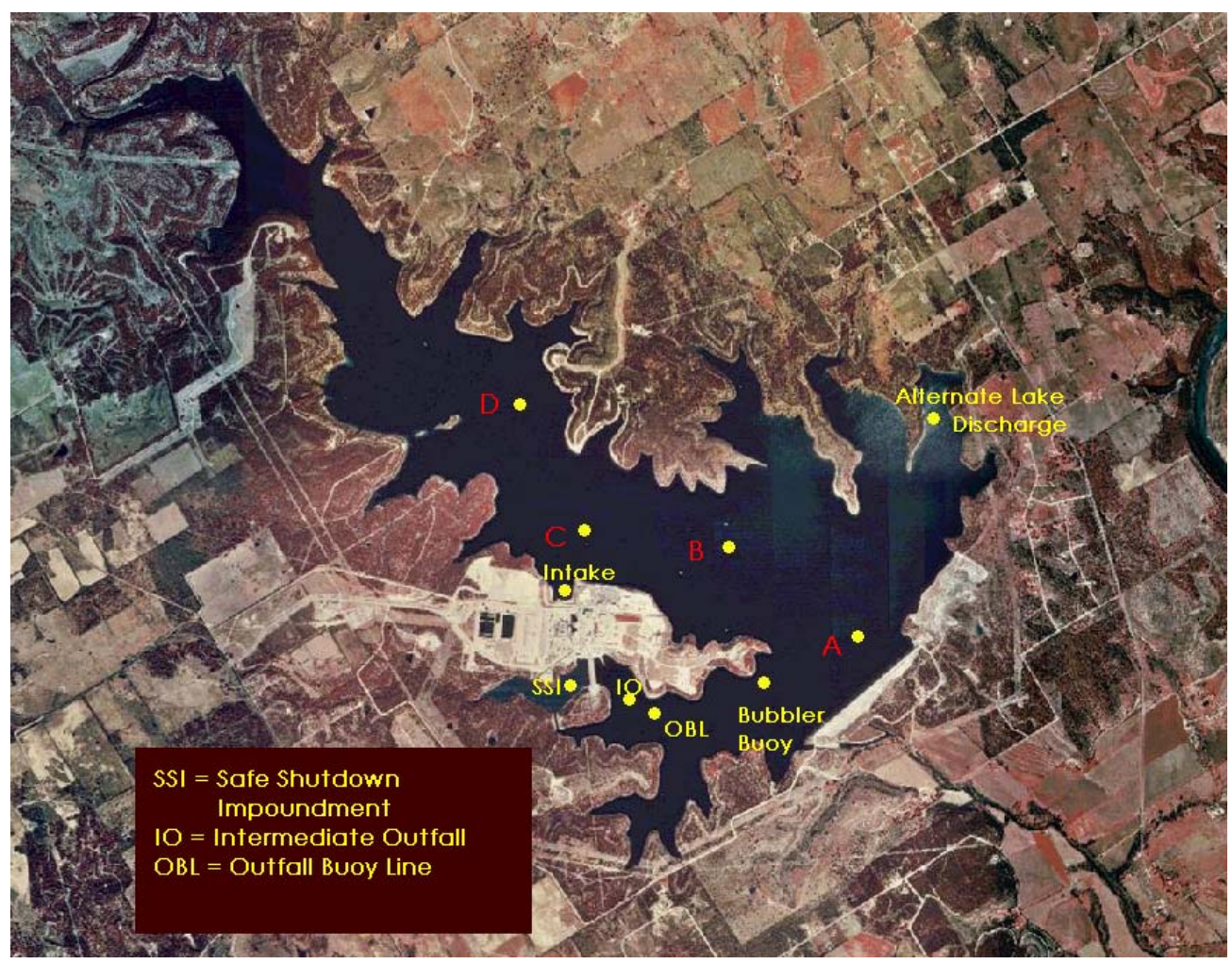

Figure 2. Location of Ground Truth Observation Buoys at Comanche Peak. 


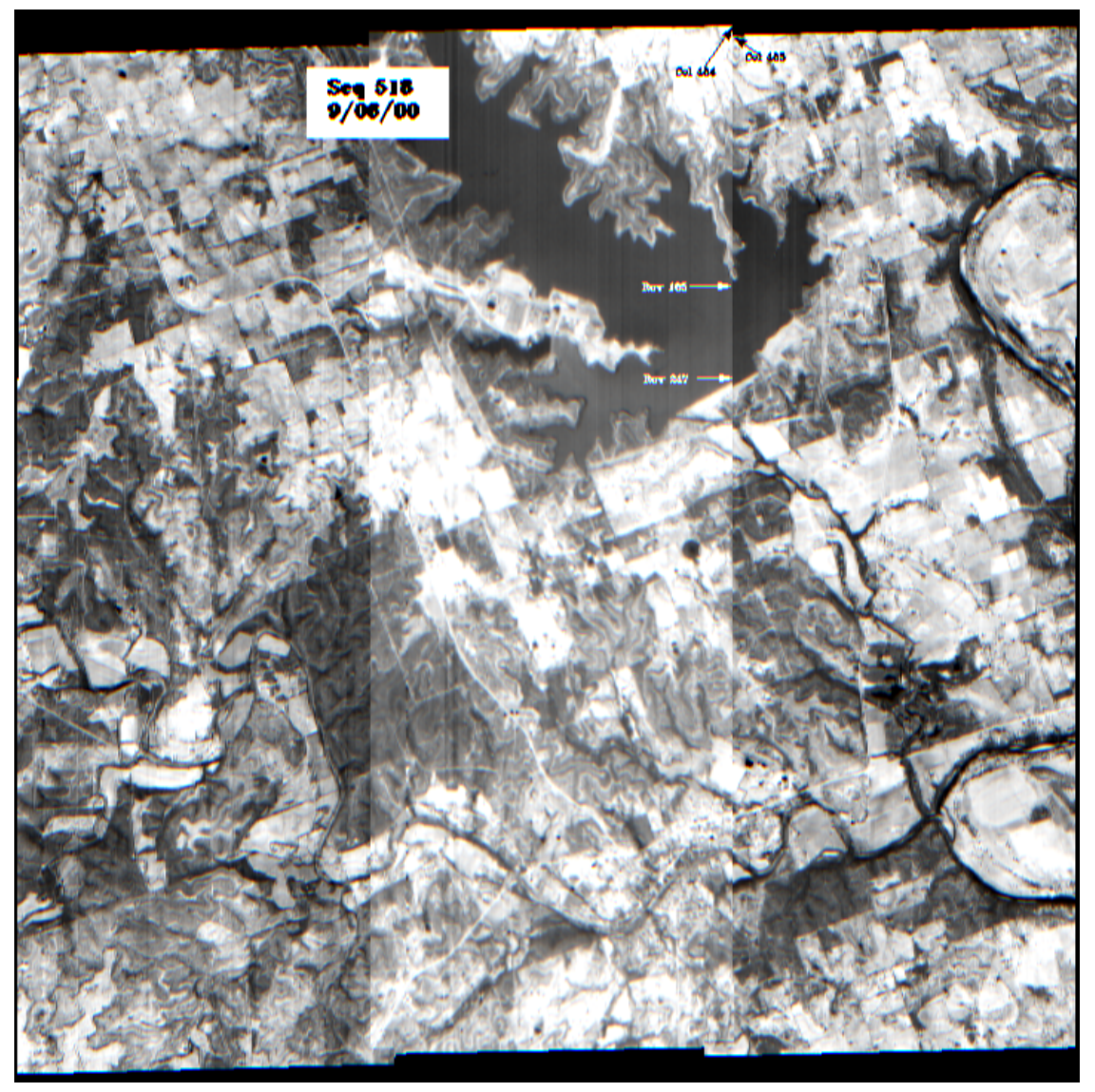

Figure 3. Water Surface Temperature image for Comanche Peak for 9/6/00. 


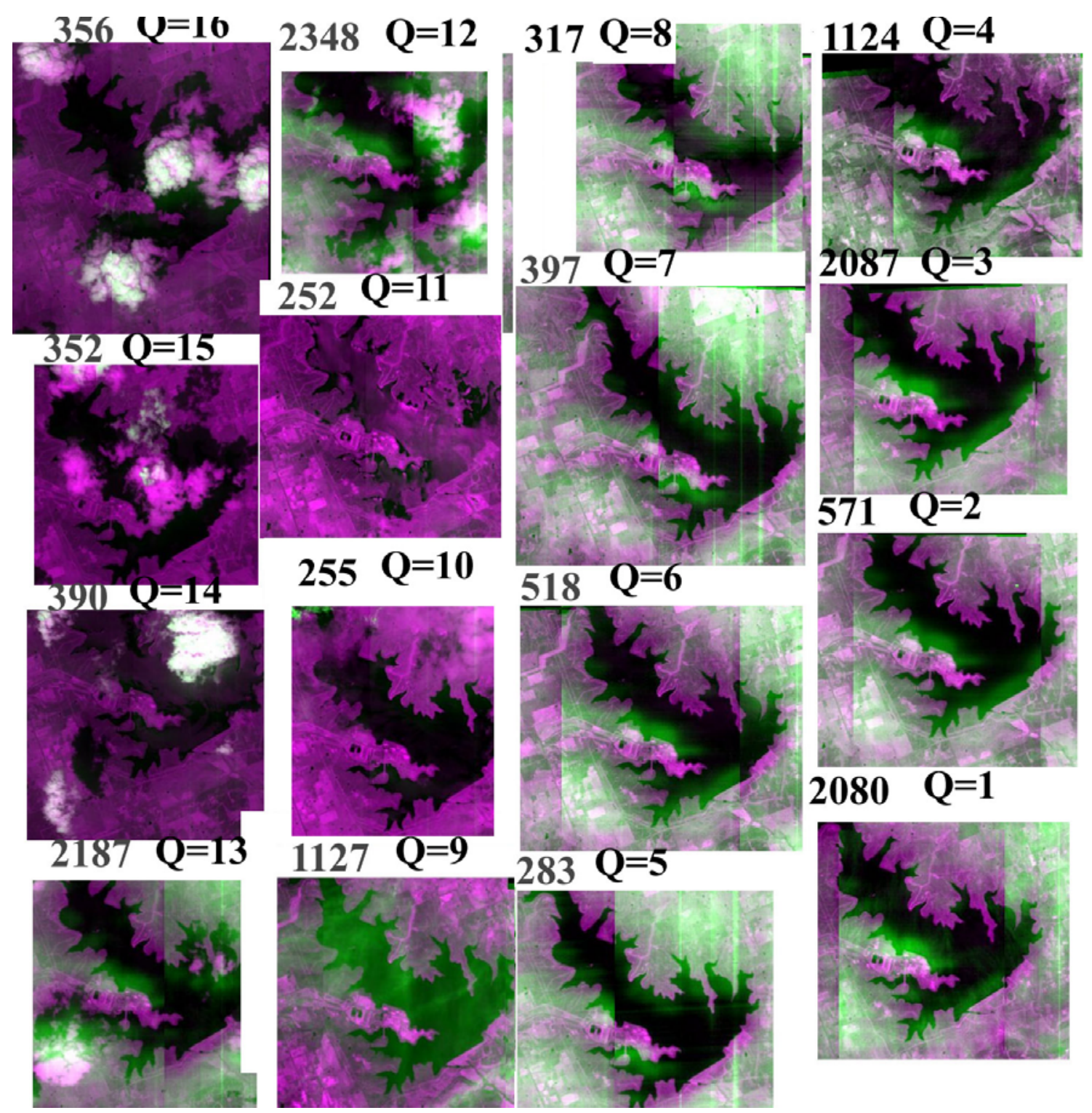

Figure 4. Image Quality for 16 Daytime MTI images of Comanche Peak. 


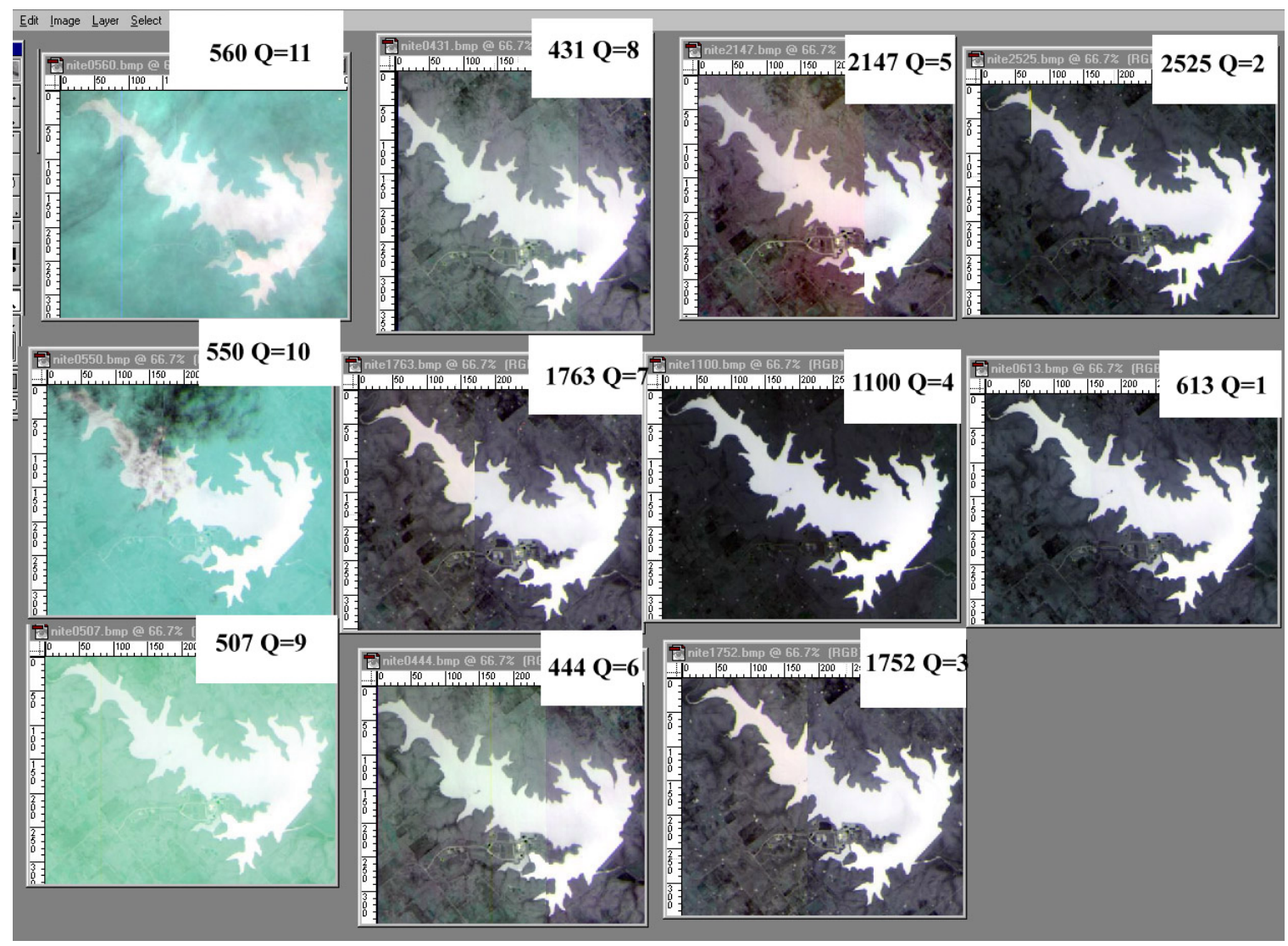

Figure 5. Quality Factor of 11 Nighttime MTI images for Comanche Peak. 


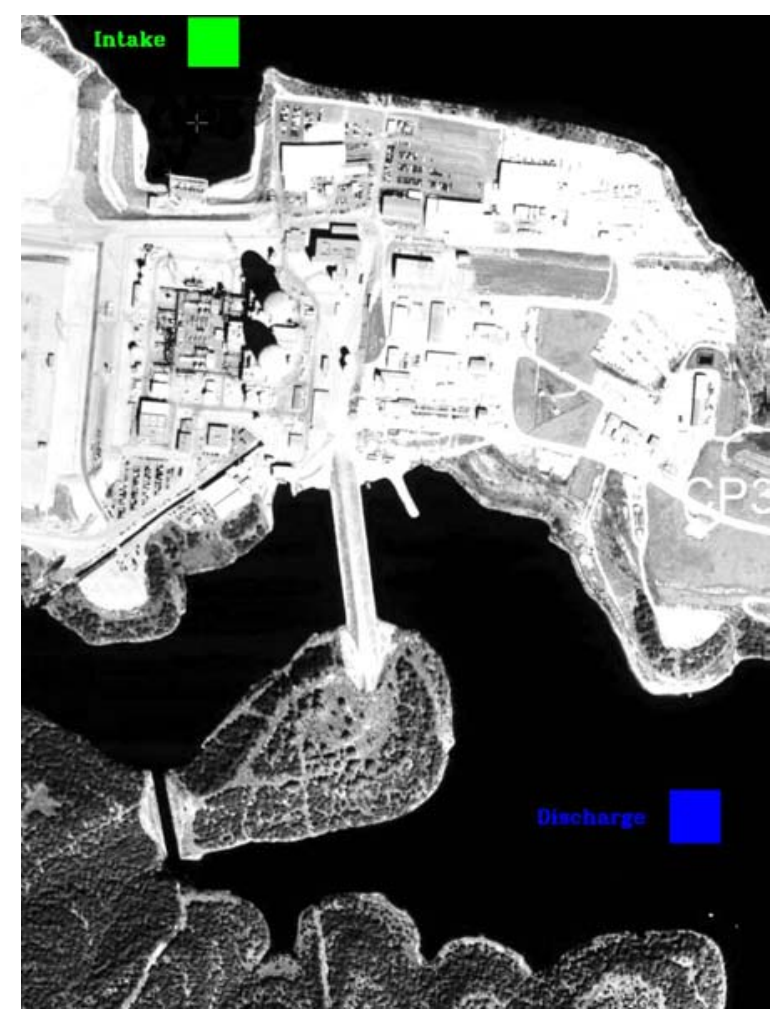

Figure 6. Sub-sampled image of Comanche Peak showing regions-of-interest associated with hot-water discharge and cold-water intake 
Water Temperature Retrieval Error and Image Quality

for Nighttime at Comanche Peak SCA 1

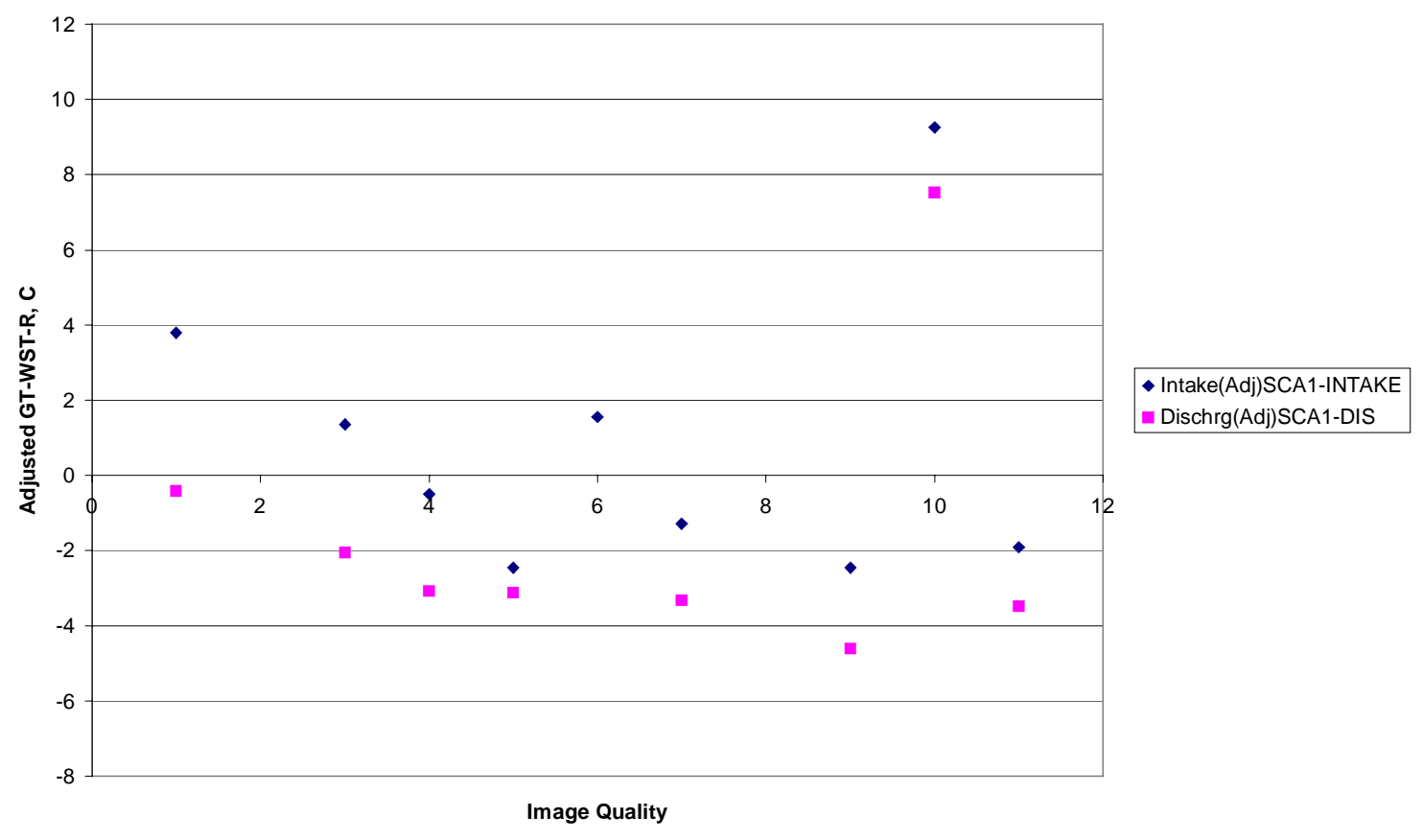

Figure 7. Water Temperature Retrieval Error and Image Quality for Nighttime at Comanche Peak SCA 1. 
Water Temperature Retrieval Error and Image Quality for Daytime at Comanche Peak SCA 1

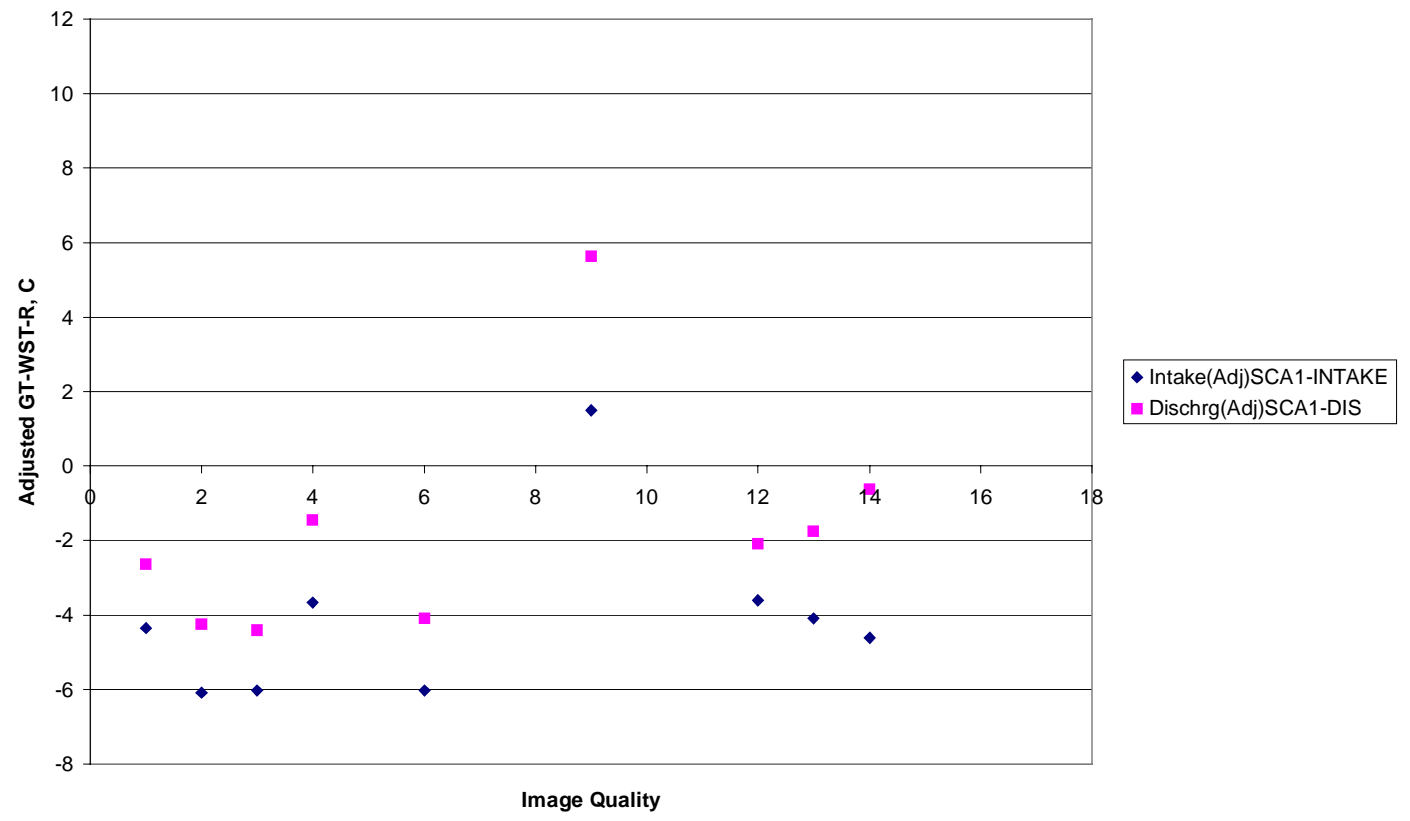

Figure 8. Water Temperature Retrieval Error and Image Quality for Daytime at Comanche Peak SCA 1. 
WSRC-TR-2002-00381

\section{Tables.}

Table 1. Coefficients for calculating WST from Top-of-Atmosphere brightness temperatures of MTI thermal bands for Zenith-to-MTI angles ranging from 0 to 40 degrees. (provided by William B. Clodius, LANL 1/28/02)

\begin{tabular}{|c|c|c|c|c|c|c|c|c|c|c|}
\hline Fit & Terms & D/N & Angle & SCA & Offset & J & K & L & M & N \\
\hline Lowtran & KLMN & D & 0 & All & 5.743 & & 0.33212 & -3.14438 & 1.90504 & 1.87483 \\
\hline Lowtran & KLMN & D & 5 & All & 5.795 & & 0.33412 & -3.15406 & 1.91016 & 1.87715 \\
\hline Lowtran & KLMN & D & 10 & All & 5.939 & & 0.3399 & -3.18222 & 1.92495 & 1.88404 \\
\hline Lowtran & KLMN & D & 15 & All & 6.21 & & 0.40727 & -3.40041 & 2.0104 & 1.94887 \\
\hline Lowtran & KLMN & D & 20 & All & 6.609 & & 0.42151 & -3.46828 & 2.04266 & 1.96835 \\
\hline Lowtran & KLMN & D & 25 & All & 7.176 & & 0.44035 & -3.55667 & 2.07981 & 1.99808 \\
\hline Lowtran & KLMN & D & 30 & All & 7.937 & & 0.46456 & -3.66945 & 2.12558 & 2.03733 \\
\hline Lowtran & KLMN & D & 35 & All & 8.959 & & 0.49464 & -3.80867 & 2.17788 & 2.08942 \\
\hline Lowtran & KLMN & D & 40 & All & 10.307 & & 0.52892 & -3.96954 & 2.23235 & 2.15537 \\
\hline & & & & & & & & & & \\
\hline Lowtran & JKLMN & $\mathrm{N}$ & 0 & All & 14.843 & 1.96669 & 0.64702 & -1.52437 & -3.54234 & 3.37936 \\
\hline Lowtran & JKLMN & $\mathrm{N}$ & 5 & All & 14.935 & 1.97006 & 0.64843 & -1.52463 & -3.55321 & 3.3853 \\
\hline Lowtran & JKLMN & $\mathrm{N}$ & 10 & All & 15.214 & 1.98006 & 0.65252 & -1.52509 & -3.58573 & 3.40298 \\
\hline Lowtran & JKLMN & $\mathrm{N}$ & 15 & All & 15.131 & 2.01508 & 0.66721 & -1.54074 & -3.6149 & 3.39894 \\
\hline Lowtran & JKLMN & $\mathrm{N}$ & 20 & All & 15.82 & 2.03828 & 0.67662 & -1.54024 & -3.69419 & 3.44213 \\
\hline Lowtran & JKLMN & $\mathrm{N}$ & 25 & All & 16.763 & 2.06801 & 0.68817 & -1.53823 & -3.79702 & 3.49761 \\
\hline Lowtran & JKLMN & $\mathrm{N}$ & 30 & All & 17.987 & 2.10568 & 0.70295 & -1.53484 & -3.92863 & 3.56809 \\
\hline Lowtran & JKLMN & $\mathrm{N}$ & 35 & All & 19.572 & 2.15121 & 0.72076 & -1.52952 & -4.0911 & 3.65506 \\
\hline Lowtran & JKLMN & $\mathrm{N}$ & 40 & All & 21.543 & 2.20745 & 0.73866 & -1.51156 & -4.28701 & 3.75045 \\
\hline
\end{tabular}


Table 2. Spatial Error of Water Surface Temperature for Long-Term Study at Comanche Peak.

\begin{tabular}{|c|c|c|}
\hline Seq No & Intake Spatial Error & Discharge Spatial Error \\
\hline 252 & 0.11 & 0.11 \\
\hline 255 & 0.08 & 0.15 \\
\hline 283 & 0.15 & 0.17 \\
\hline 317 & 0.12 & 0.26 \\
\hline 352 & 0.25 & 0.27 \\
\hline 356 & 0.13 & 0.18 \\
\hline 390 & 0.18 & 0.18 \\
\hline 397 & 0.14 & 0.14 \\
\hline 431 & 0.33 & 0.20 \\
\hline 444 & 0.19 & 0.25 \\
\hline 507 & 0.18 & 0.14 \\
\hline 518 & 0.11 & 0.15 \\
\hline 550 & 0.24 & 0.37 \\
\hline 571 & 0.12 & 0.20 \\
\hline 613 & 0.35 & 0.23 \\
\hline 1024 & 0.28 & 0.18 \\
\hline 1100 & 0.34 & 0.29 \\
\hline 1127 & 0.24 & 0.14 \\
\hline 1752 & 0.23 & 0.37 \\
\hline 1763 & 0.17 & 0.18 \\
\hline 2080 & 0.13 & 0.13 \\
\hline 2087 & 0.18 & 0.13 \\
\hline 2147 & 0.19 & 0.16 \\
\hline 2187 & 0.10 & 0.09 \\
\hline 2348 & 0.07 & 0.18 \\
\hline 2525 & 0.29 & 0.43 \\
\hline Ave & 0.19 & 0.20 \\
\hline Min & 0.07 & 0.09 \\
\hline Max & 0.35 & 0.43 \\
\hline
\end{tabular}


Table 3. Error Analysis of Water Surface Temperature for Long-Term Study at Comanche Peak.

\begin{tabular}{|c|c|c|c|c|}
\hline & \multicolumn{2}{|c|}{ Intake } & \multicolumn{2}{c|}{ Discharge } \\
\hline Type Error & Average & Maximum & Average & Maxium \\
\hline Sensor Accuracy & 0.20 & 0.20 & 0.20 & 0.20 \\
\hline Skin Temperature Adjustment & 0.20 & 0.20 & 0.20 & 0.20 \\
\hline Spatial Variation & 0.19 & 0.35 & 0.20 & 0.43 \\
\hline Total Error, deg C & 0.34 & 0.45 & 0.35 & 0.52 \\
\hline
\end{tabular}

Table 4. Spatial Error of Water Surface Temperature for Short-Term Study at Comanche Peak .

\begin{tabular}{|c|c|c|c|c|c|c|c|c|c|c|}
\hline MTI IMAGE & SSI & OUTF1 & OUTF2 & BUB & ALTL & SIT A & SIT B & SIT C & SIT D & FENC \\
\hline r1_109330 & 0.20 & 0.45 & 0.92 & 0.31 & 0.75 & 0.36 & 0.17 & 0.10 & 0.13 & 0.49 \\
\hline r1_109379 & 0.11 & 0.37 & 0.39 & 0.19 & 0.71 & 0.45 & 0.10 & 0.31 & 0.21 & 0.28 \\
\hline r1_109410 & 0.13 & 1.97 & 1.47 & 0.67 & 0.11 & 0.52 & 0.39 & 0.09 & 0.05 & 0.57 \\
\hline r1_109445 & 0.21 & 0.35 & 0.50 & 0.20 & 0.17 & 0.16 & 0.18 & 0.14 & 0.22 & 1.09 \\
\hline r1_109479 & 0.22 & 0.21 & 0.10 & 0.27 & 0.28 & 0.50 & 0.07 & 0.08 & 0.27 & 0.13 \\
\hline r1_109509 & 0.16 & 0.87 & 1.19 & 0.40 & 0.25 & 0.08 & 0.42 & 1.54 & 0.43 & 2.21 \\
\hline r1_109574 & 0.43 & 0.27 & 0.30 & 0.24 & 0.14 & 0.16 & 0.08 & 0.10 & 0.12 & 0.93 \\
\hline r1_109606 & 0.12 & 0.23 & 0.12 & 0.30 & 0.18 & 0.20 & 0.07 & 0.07 & 0.15 & 0.28 \\
\hline Ave r1 & 0.20 & 0.59 & 0.62 & 0.32 & 0.32 & 0.30 & 0.19 & 0.30 & 0.20 & 0.75 \\
\hline Min r1 & 0.11 & 0.21 & 0.10 & 0.19 & 0.11 & 0.08 & 0.07 & 0.07 & 0.05 & 0.13 \\
\hline Max r1 & 0.43 & 1.97 & 1.47 & 0.67 & 0.75 & 0.52 & 0.42 & 1.54 & 0.43 & 2.21 \\
\hline
\end{tabular}

Table 5. Error Analysis for Water Surface Temperature for Short-Term Study at Comanche Peak .

\begin{tabular}{|l|c|c|c|c|}
\hline & \multicolumn{2}{|c|}{ Near-Shore Buoys } & \multicolumn{2}{c|}{ Open-Water Buoys } \\
\hline Type Error & Average & Average Max. & Average & Average Max. \\
\hline Sensor Accuracy & 0.20 & 0.20 & 0.20 & 0.20 \\
\hline Skin Temperature Adjustment & 0.20 & 0.20 & 0.20 & 0.20 \\
\hline Spatial Variation & 0.47 & 1.35 & 0.25 & 0.73 \\
\hline Total Error, deg C & $\mathbf{0 . 5 5}$ & $\mathbf{1 . 3 8}$ & $\mathbf{0 . 3 8}$ & $\mathbf{0 . 7 8}$ \\
\hline
\end{tabular}




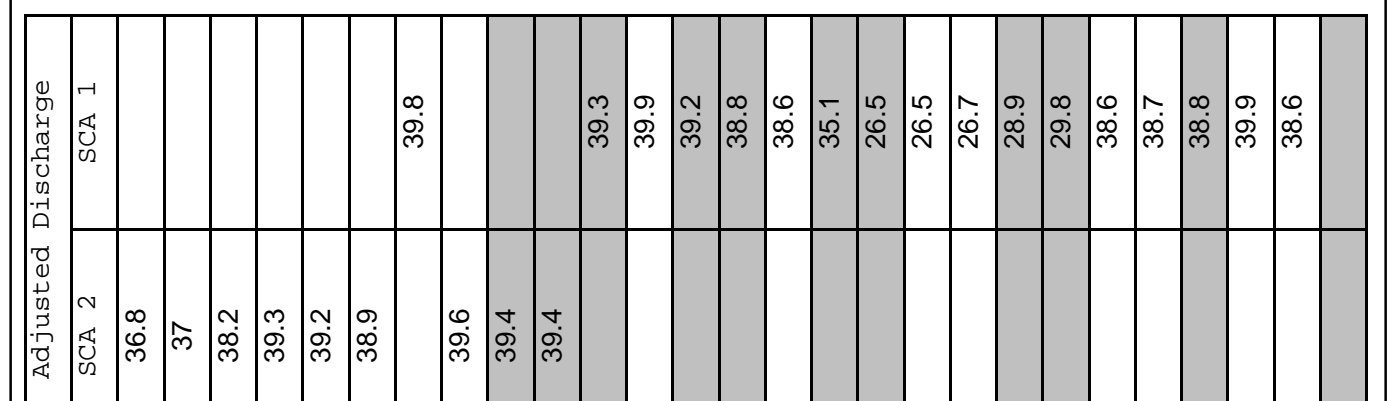

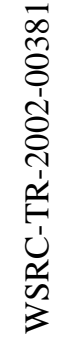

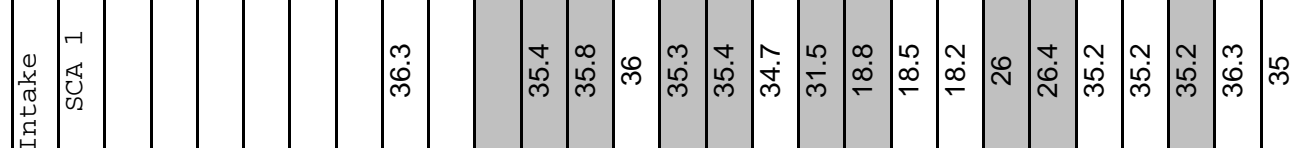

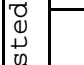

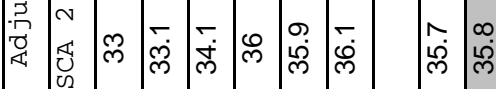

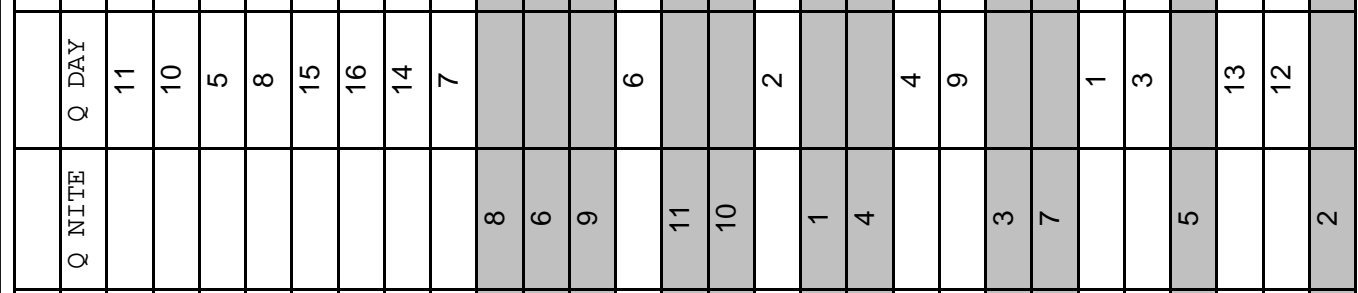

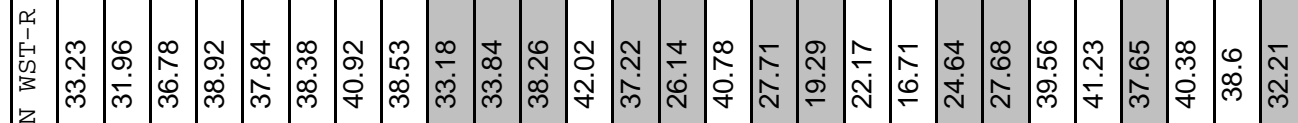
貟

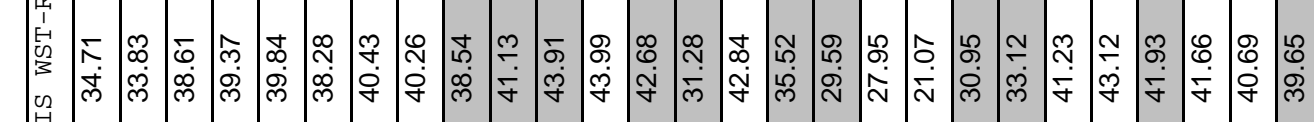

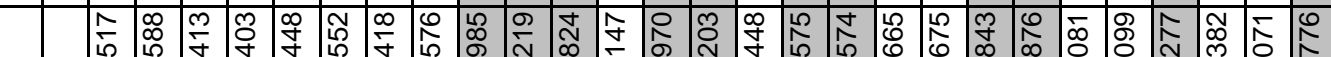
苾 草

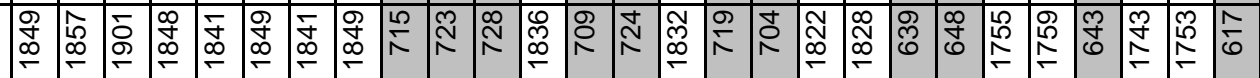

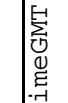

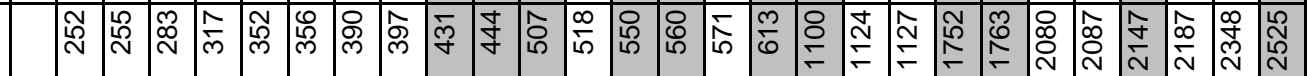
$\#$
O
0
0
0

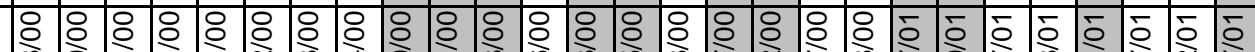
-

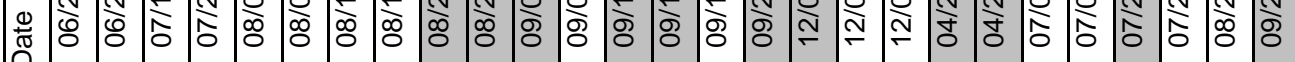




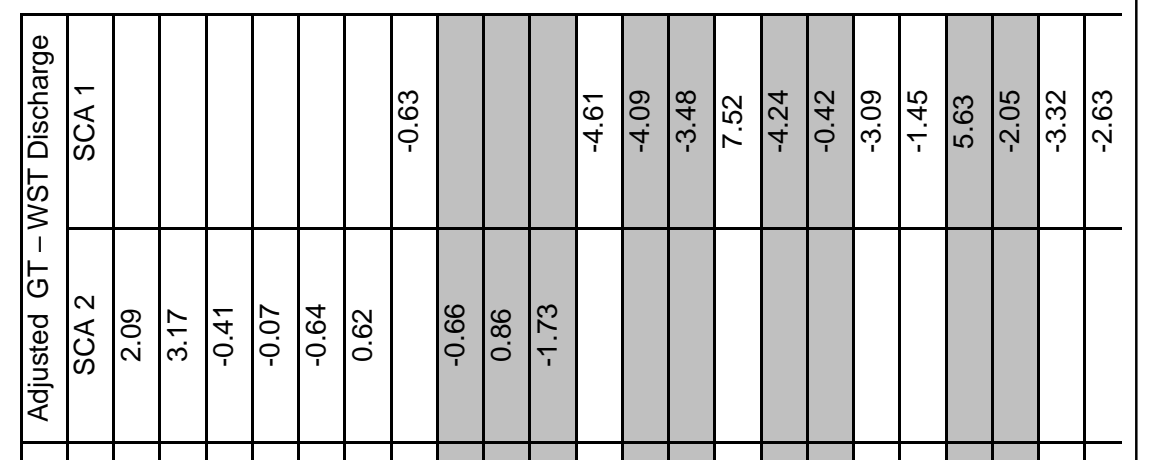

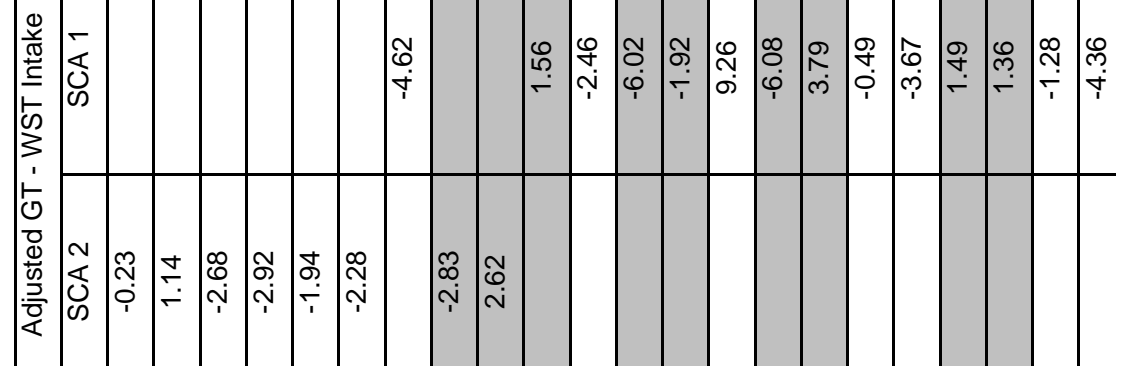

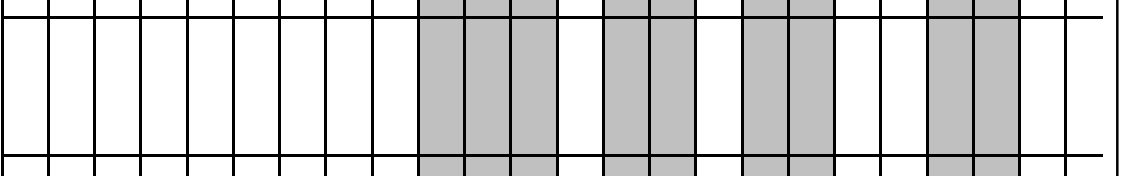

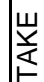

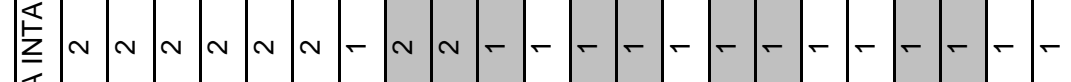
迥

$\frac{D}{0}$

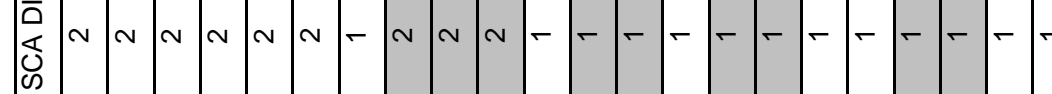

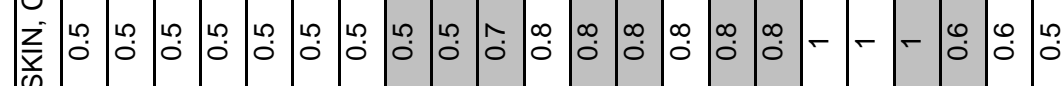

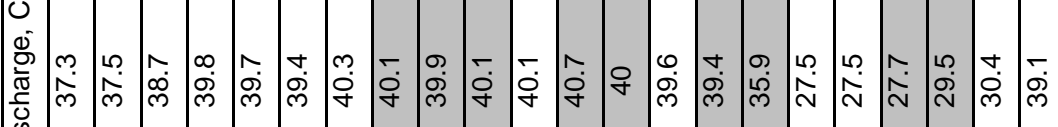
峁

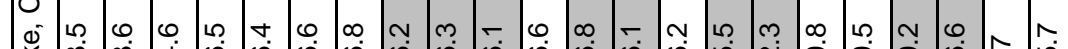

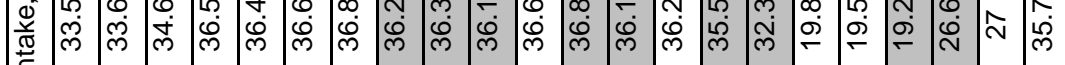

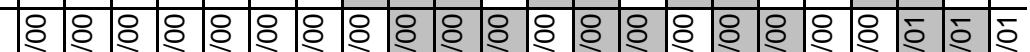
急 ๑ 


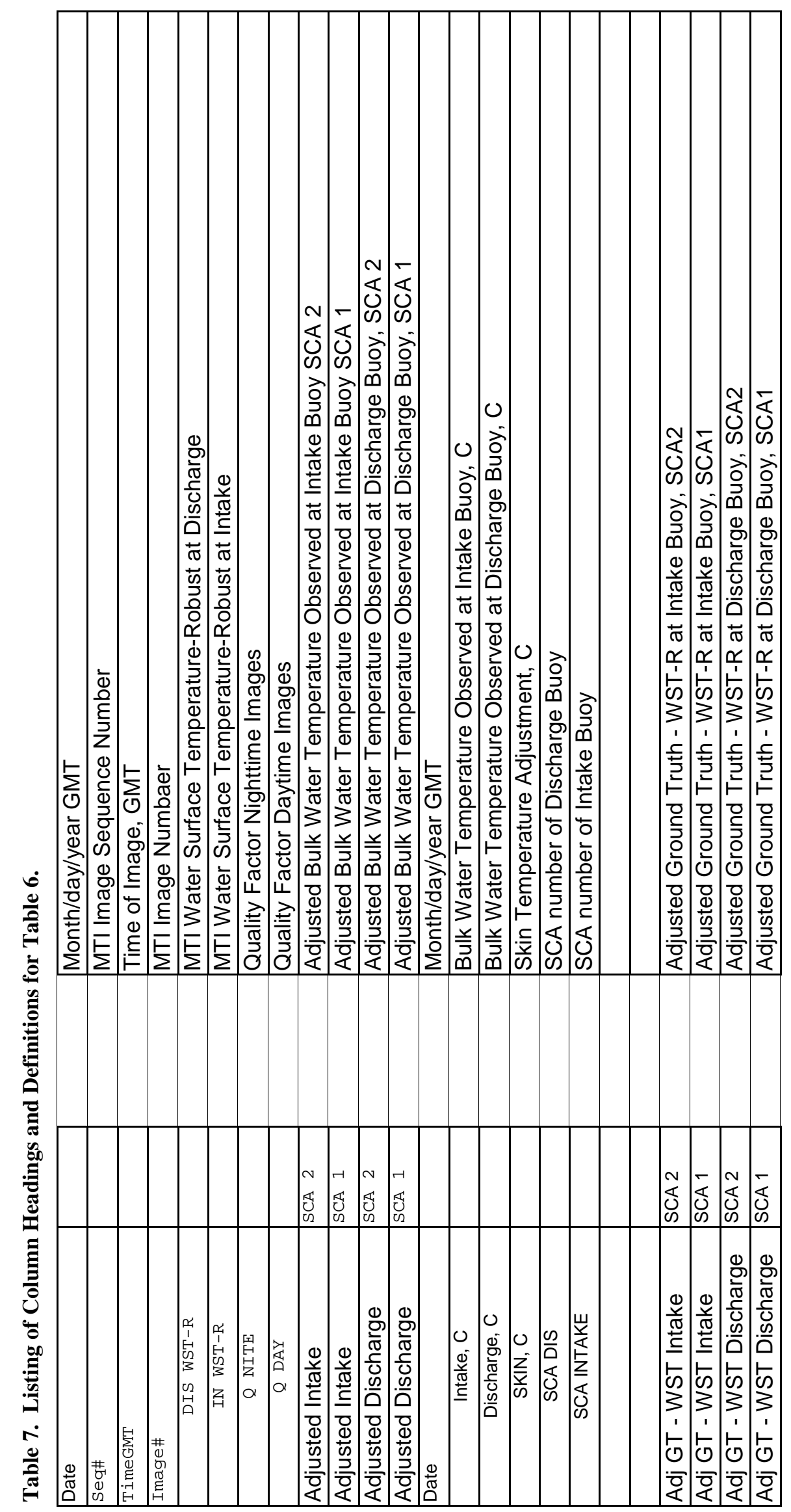




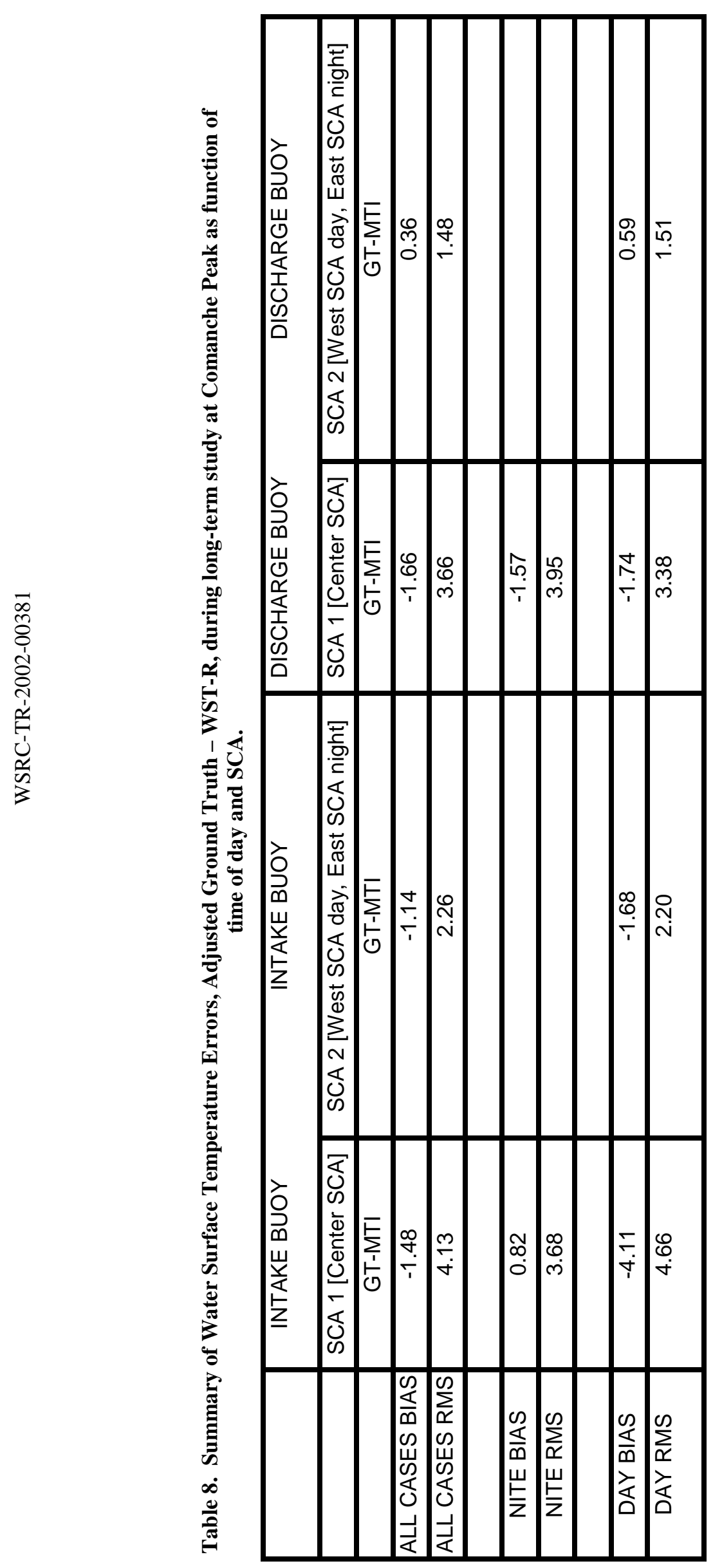




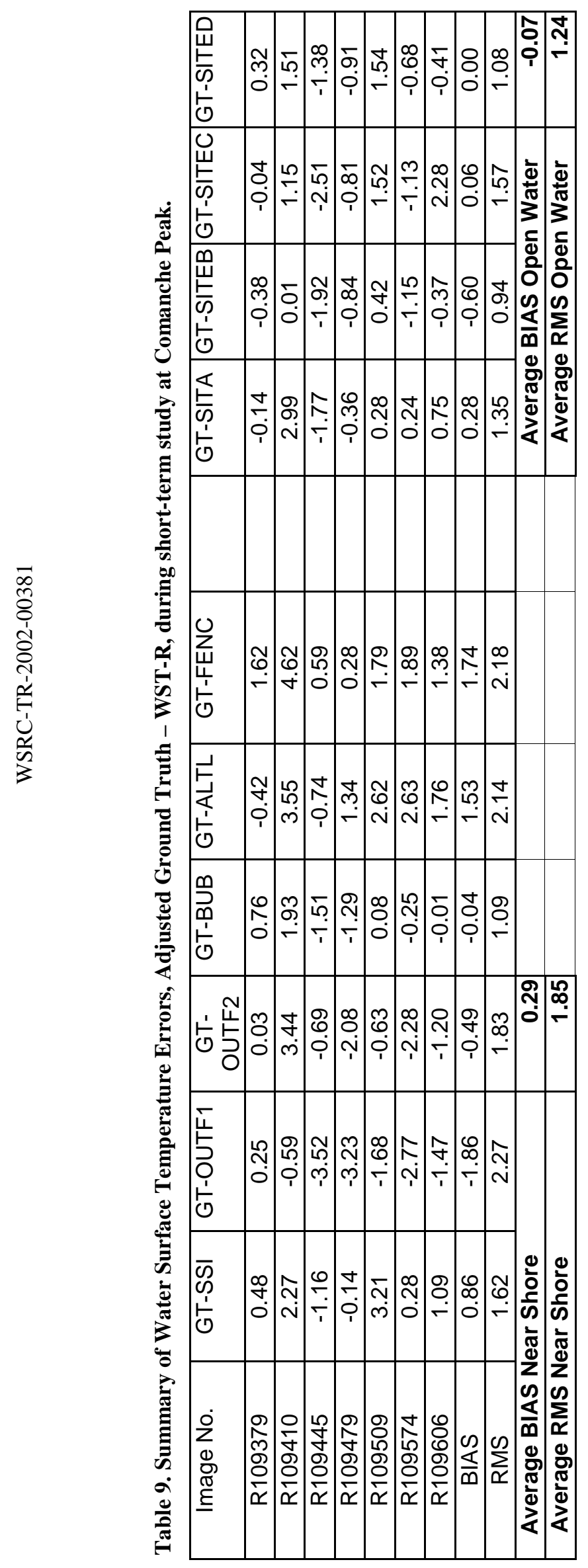

